\title{
A metrópole moderna, o olhar surrealista: considerações benjaminianas
}

\section{Walter Benjamin's approach to the modern metropolis and the glance surrealistic}

\author{
Vanessa Madrona Moreira Salles* \\ Fundação Mineira de Educação e Cultura - FUMEC, Belo Horizonte - MG, Brasil
}

\begin{abstract}
RESUMO
Walter Benjamin intenta apresentar a cidade, em sua multiplicidade e diversidade, como espaço de experiência sensorial e intelectual, local de encenação dos conflitos sociais e de transformações urbanísticas. Suas ruas são palco de circulação de mercadorias, repletas de enigmas; o lugar onde o sujeito autônomo, senhor de uma razão iluminista, perde-se em meio a uma labiríntica multidão - de pessoas, de objetos, de imagens -, e em que a experiência de rapidez, de anonimato pode ser realizada de modo mais radical do que em qualquer outro lugar. Desse modo, ler a cidade é ler um mosaico, e Benjamin retoma uma das mais profícuas leituras da metrópole urbana: a visada surrealista.
\end{abstract}

Palavras-chave: Metrópole, Surrealismo, Benjamin.

\begin{abstract}
Walter Benjamin aims to present the different and multiple aspects of modern city. It is seen as the place where men have sensorial and intellectual experience, where social conflicts and urban transformations take place. In the streets of the city goods are sold and bought and they are mysterious and cannot be understood at once. In the street of modern city autonomous citizen, guided by enlighted thinking, cannot distinguish himself among a huge crowd of people, objects and images. In this very context, he does feel the speed things change and his own anonymous presence. The city can only be read as a mosaic and Walter Benjamin tries to understand it in the surrealistic way that he considers the richest form of doing so.
\end{abstract}

Keywords: Metropolis, Surrealism, Benjamin.

(...) a liberdade adquirida nesta vida ao preço de inúmeras e dificílimas renúncias, exige ser usufruída sem restrições no tempo em que é dada, sem considerações pragmáticas de nenhuma espécie, e isso porque a emancipação humana, definitivamente concebida sob a forma revolucionária mais simples, que nem por isso, entendamo-nos, deixa de ser a emancipação humana a todos os respeitos, segundo os meios de que cada um dispõe, é a única causa que continua a ser digna de ser servida. 
(BRETON, 1972, p. 123).

Benjamin apresenta as ruas das metrópoles modernas como "morada do coletivo" e local de exercício do poder político, onde as escolhas urbanísticas têm intenções subjacentes de controle das massas, como as que se evidenciam nas reformas de Haussmann ${ }^{1}$, na Paris do século XIX. Esta reforma urbanística poderia ser vista equivocadamente como sintoma de uma modernidade que caminha a passos largos em direção à consolidação do domínio do homem sobre a natureza, uma espécie de segunda natureza, cujo ritmo progressivo é tomado como inexorável e positivo. Resulta, portanto, um efeito perverso: provoca "nos parisienses estranhamento em relação à sua cidade. Nela não se sentem mais em casa. Começam a tomar consciência do caráter desumano da grande cidade" (BENJAMIN, 2006, p.49). O que, aos olhos do engenheiro parecem formas urbanísticas de dominação surge, para a maioria dos moradores de Paris, como ameaça.

Os edifícios de Haussmann são a representação perfeitamente adequada dos princípios do regime imperial absoluto, emparedados numa eternidade maciça: repressão de qualquer organização individual, de qualquer autodesenvolvimento orgânico, 'o ódio fundamental de toda individualidade'. ${ }^{2}$

O tema da cidade encontra-se presente em vários momentos do itinerário intelectual de Benjamin. Em 1923, ele traduz para o alemão os Tableaux parisiens, de Baudelaire. No final da década de 20 surgem Rua de mão única, Diário de Moscou e a série radiofônica sobre Berlim. Crônica berlinense e Infância em Berlim por volta de 1900 são publicados nos anos 30 e o ensaísta dedica-se às Passagens entre os anos de 1927 até sua morte, em 1940.

Walter Benjamin apresenta uma metrópole moderna ${ }^{3}$ enquanto imagem mental. Nesta imagem reúnem-se retratos urbanos de várias cidades concretas ${ }^{4}$, que ele conheceu: Berlim, Paris, Moscou ${ }^{5}$, Nápoles ${ }^{6}$, dentre outras. Seus escritos intentam representar a cidade em sua multiplicidade e diversidade, como espaço de experiência sensorial e intelectual, local de encenação dos conflitos sociais e de transformações urbanísticas. Suas ruas são palco de circulação de mercadorias - objetos e pessoas - repletas de enigmas; o lugar onde o sujeito autônomo, senhor de uma razão iluminista, perde-se em meio a uma labiríntica multidão, "onde ninguém é para o outro nem totalmente nítido, nem totalmente opaco" (BENJ AMIN, 1989, p. 46). A cidade é vista como espaço de trânsito e diferença, onde a experiência de rapidez, de multiplicidade, de anonimato pode ser realizada de modo mais radical do que em qualquer outro lugar. 
A metrópole moderna discutida por Benjamin está incrustada em uma época de grandes transformações: o século XIX. O processo de industrialização e mercantilização se intensificam, neste período, de forma extraordinária. A consciência que esta época tem de si mesma é o que chamamos modernidade. Mas como é a ordem burguesa capitalista que rege a modernidade, esta metamorfoseia o que de fato é mera repetição sob o disfarce do novo. Desta forma, a modernidade é, nas palavras de Willi Bolle (1994), "essencialmente hostil ao desenvolvimento pleno do ser humano" (p. 84).

A tarefa crítica assumida por Benjamin é decifrar a "mitologia da modernidade", mitologia aqui entendida como ideologia falseadora, que aposta cegamente num projeto logocêntrico sob o signo do progresso.

O mito pressupõe a temporalidade do eterno retorno e a onipresença de um destino inexorável, a contrapelo da capacidade humana de intervenção no curso dos acontecimentos que se apresenta como pressuposto da história. No mundo moderno o mito persiste tanto em explicações teológicas quanto científicas, ou seja, como discurso fatalista que afirma a predeterminação dos fatos negando-lhes a historicidade. Benjamin combate alguns mitos: o mito do progresso histórico decorrente do avanço tecnológico; o mito da evolução social, que identifica o barbarismo da história como natural, sob os auspícios da eternidade dos sofrimentos.

Em Passagens, Benjamin descreve a consciência da metrópole através de uma diversidade perceptiva. Compreender a cidade é colocar-se diante de um caleidoscópio, de onde não se veem somente belas imagens. A visão caleidoscópica implica em ação do observador, que agita os fragmentos coloridos formando novas constelações de formas, criando mosaicos. Na metrópole urbana vários são os transeuntes que percorrem as ruas da cidade, que cultivam fantasmagorias do espaço e do tempo. Cada um anuncia uma forma de visualidade.

O industrial passa sobre o asfalto apreciando sua qualidade; o velho procura-o com cuidado, seguindo por ele tanto quanto possível e fazendo alegremente ressoar nele sua bengala, lembrando-se com orgulho que viu construir as primeiras calçadas; o poeta (...) anda pelo asfalto indiferente e pensativo, mastigando versos; o corretor da bolsa o percorre calculando as oportunidades da última alta da farinha; e o desatento, escorrega. ${ }^{7}$

Para Benjamin, a percepção da cidade implica em interpretar não apenas os signos explícitos, mas, especialmente, ater-se aos dejetos, ao efêmero, ao desprezado. O que pretendemos analisar aqui são alguns elementos de uma estratégia hermenêutica adotada pelos surrealistas André Breton e Louis Aragon que se apóia no poder 
interpretativo de imagens, estratégia esta que será retomada por Benjamin.

I. Na primeira metade da década de 20, Benjamin acolhe como objeto de seus estudos momentos importantes da história da literatura alemã - especialmente, o Romantismo e o Barroco ${ }^{8}$. Nestes trabalhos observa-se um duplo procedimento: crítica à unicidade da obra de arte, defendida por uma ampla tradição crítica, e o resgate do que fora desprestigiado por essa mesma tradição, como, por exemplo, os dramas barrocos alemães. Em Origem do drama barroco alemão, o ensaísta destaca ainda uma mudança de foco de abordagem da obra de arte: desenvolve uma crítica em que o fragmento, o estilhaço, assume uma importância própria, autônoma, e passa a ter uma existência que prescinde de qualquer participação anterior em alguma totalidade. É na contemplação do detalhe, das frações, que se atinge a verdade. Mas, somente a partir de 1924 seus escritos tratarão da cultura europeia do século XX, sob influxos marxistas.

Foi como berlinense que Benjamin entrou em contato com as vanguardas européias ${ }^{9}$. A capital alemã era o centro europeu de fomento de experiências artísticas - cinema, música, artes plásticas, arquitetura, etc. - na década de 20. É também devido a sua condição de habitante de Berlim que o ensaísta tem propriedade para abordar a experiência vivida por sua geração: o esfacelamento de certezas, a fragmentação da vida vivenciada sob a fragilizada - moral e economicamente - República de Weimar. Benjamin cria uma espécie de mosaico em seus escritos a partir do final dos anos vinte, em sintonia formal com sua conturbada época, marcada, destacadamente, entre vários outros fenômenos sociais, pela Primeira Guerra e a iminência de uma segunda e por mudanças políticas inauditas, como a Revolução Russa ${ }^{10}$.

Em carta enviada a Hofmannsthal, em 5 de junho de 1927, Benjamin fala de sua sensação de inadequação no ambiente intelectual alemão e sua afinidade com o movimento surrealista francês ${ }^{11}$.

Podemos, pois, destacar como lugar de convergência entre Benjamin e o movimento surrealista a escolha privilegiada da cidade moderna como "objeto" de análise e, sobretudo, uma relação afetiva com a cidade de Paris ${ }^{12}$. Louis Aragon, André Breton e Walter Benjamin buscam apreender a significação da cidade moderna em sua materialidade efêmera ${ }^{13}$ e constatam que a mesma se encontra sob o império da mitologia da modernidade.

Aragon e Breton apresentam uma visão da modernidade como sendo o momento de um re-encantamento do mundo, na contramão da leitura weberiana que assinala a desmistificação do mundo como sendo princípio fundante do projeto da modernidade. O sujeito surrealista vagueia por entre objetos, formas, espaços, fadados à 
inexistência, numa configuração histórica e profana. Constata que nada é eterno, que a cidade está sob o império da transitoriedade, que o mundo moderno é um sonho envolto em poderes míticos.

O tema da "mitologia da modernidade" discutido, especialmente, nas Passagens, foi tomado de empréstimo de Louis Aragon - $O$ camponês de Paris (1926), assim como a referência às passagens parisienses. Alguns instantâneos do olhar surrealista de Aragon sobre a cidade serão apropriados por Benjamin em sua reflexão sobre a capital do século XIX.

$\mathrm{Na}$ perspectiva surrealista, a cidade de Paris é apresentada sob pontos de vista diversos. Não é a cidade resultante de planejamento e intervenções urbanísticas de engenheiros e arquitetos. Em $\mathrm{O}$ camponês de Paris Aragon destaca dois locais na cidade - a Passagem da Ópera e o parque Buttes-Chaumont. André Breton tem uma Paris mapeada conforme seus encontros com uma mulher, a surpreendente Nadja de olhar enigmático, misteriosa como a cidade. "Que haverá de tão extraordinário neste olhar? Que se reflete nos seus olhos com tanta sombra e tanta luz? Donde virá tamanha aflição, um orgulho assim?" (BRETON, 1972, p. 55).

No título do romance de Aragon, O camponês de Paris, temos que a palavra camponês remete conceitualmente a condições de sociabilidade estabelecidas no campo, portanto, uma percepção não urbana, cujo ritmo é lento e constante. No entanto, este será um camponês diferente, pois seu olhar ensimesmado terá diante dos olhos a célere e mutante capital francesa: Paris. O próprio título nos dá, assim, uma pista da operação surrealista: reunir imagens aparentemente díspares em uma nova constelação.

O camponês de Paris é o próprio Aragon que, para observar sua cidade - ele é parisiense -, vaga por suas ruas com um olhar de outrem, de forasteiro, atento à cidade, aos seus monumentos, edifícios, habitantes, ruas, jardins, parques, não se sujeitando ao embotamento da percepção que acomete os nativos que adquirem um olhar que se habitua ao que está diante dos olhos, e, por isso, deixa de ver criticamente ${ }^{14}$. Ele busca a "luz moderna do insólito" que reina

(...) extravagantemente nessas espécies de galerias cobertas que são numerosas, em Paris, nos arredores dos grandes boulevards e que se chamam, de maneira desconcertante de passagens, como se nesses corredores ocultados do dia não fosse permitido a ninguém deter-se por mais de um instante. (ARAGON, 1996, p.44)

Este livro sobre Paris adquirirá posteriormente um valor de nota necrológica visto que a Passagem da Ópera será demolida em 1924, para dar continuidade às obras de construção do boulevard Haussmann. Esse empreendimento, em sua fúria destruidora, 
tombará casas e destruirá vias, provavelmente modificará "todo o curso dos pensamentos de um bairro e, talvez do mundo" (ARAGON, 1996 , p. 45), pois, segundo Aragon, o espaço plasma os pensamentos.

A Passagem da Ópera, no limiar de sua extinção, é conjunto de ruínas que fala de um passado e anuncia um futuro, marcado pelo signo da transformação ininterrupta. Este lugar de trânsito, em direção à inexistência, será percorrido pelas palavras do poeta, que, num ritmo alucinado, numa "escrita automática" regida pela imaginação, aqui entendida como produção de imagem, observa atentamente a cidade, em sua representação monadológica: a descrição da Passagem da Ópera mostra-nos Paris, mas o palimpsesto é a história do homem moderno.

Os passos do poeta são errantes, sendo a experiência do "erro" a única possível num mundo em que a ordem não é visível ${ }^{15}$.

Há no mundo uma desordem impensável e é extraordinário que, de forma ordinária, os homens tenham buscado, sob a aparência da desordem, uma ordem misteriosa que lhes é natural (...). O espírito do homem não suporta a desordem porque não pode pensá-la. (ARAGON, 1996, p.215).

De fato, não há erro, mas o temor do engano instaurado no pensamento moderno por Descartes, o qual, para ser aplacado, postula a necessidade da evidência, esforça-se para distinguir a verdade do erro e se afastar das percepções que podem enganar Breton também "duvida" das certezas cartesianas e segue o mesmo raciocínio de Aragon ao avaliar a "loucura" de Nadja, que fora internada em um hospício. Expõe o poeta:

(...) não penso que para Nadja haja uma extrema diferença entre o interior e o exterior de um manicômio. (...) Haverá algo mais odioso do que estes aparelhos ditos de conservação social que por um pecadilho, uma primeira falta exterior à decadência ou ao senso comum [eis a "ordem"!] precipitam qualquer indivíduo no meio de criaturas cujo trato só lhe pode ser nefasto? (BRETON, 1972, p. 117-118)

A bem conhecida ausência de qualquer fronteira entre a nãoloucura e a loucura não me predispõe a conceber valor diferente às percepções e às idéias que são do foro de uma ou de outra. (BRETON, 1972, p. 124)

Aragon nos aponta o que não quer: "não quero mais me abster dos erros de meus dedos, dos erros de meus olhos. Sei agora que eles não são armadilhas grosseiras, mas sim, curiosos caminhos em direção a um objetivo que nada, além deles, pode me revelar." (ARAGON, 1996, p. 42). 
Para realizar seu desejo o parisiense se faz campesino, também no sentido de depositar sobre a cidade um olhar arcaico, primitivo, infantil.

\begin{abstract}
No mundo da criança não há distinção clara entre realidade e aparência. Ela usa os mais inesperados instrumentos para os fins mais inesperados - uma mesa de cabeça para baixo como nave espacial, uma bacia como capacete de aço. No contexto do jogo, servem a esses propósitos perfeitamente. A bacia não 'representa' um capacete, ela é uma espécie de capacete improvisado e pode até dar provas da sua utilidade como tal. Não existe divisão rígida entre fantasma e realidade, verdade e impostura, pelo menos até onde a intenção e a ação humanas mantêm suas posições próprias. (GOMBRICH, 2007, p. 84-85)
\end{abstract}

A percepção infantil não se conforma ao que é prescrito pelos adultos para ser visto, mas se sujeita ao assustador que se encontra oculto na vida material. Assim também procederá o flâneur surrealista que com olhar arguto e microscópico recolhe o insólito neste "aquário humano" - a passagem em vias de extinção. Neste momento derradeiro, transforma-se no santuário "dum culto do efêmero, na paisagem fantasmática dos prazeres e das profissões malditas, incompreensíveis hoje, e que o amanhã não conhecerá jamais" (ARAGON, 1996, p. 45). A destruição da Passagem da Ópera é uma imagem emblemática da ação da história nos tempos modernos.

A prática surrealista consiste justamente em "recolocar no pensamento as imagens". Reúne imagens de maneira inaudita "a fim de desconcertar o mundo exterior, a fim de desalojar as imagens do mundo exterior do lugar que elas tinham tomado o hábito de ocupar" (CASSOU, 1962, p. 423). A empreitada surrealista regula-se pelo produto da imaginação, a saber, por imagens dispostas num ritmo desregulado e passional. O que interessa é o jogo de imagens.

Breton, em Nadja, joga com as imagens dos lugares percorridos pelos protagonistas, teatros, bares, galerias, monumentos, cinemas, hotéis, ruas e boulevares, incluindo-as em seu pensamento. Este jogo também se efetiva, no romance de Aragon, na deambulação da personagem que olha os detalhes que compõem a Passagem da Ópera - seus prédios, seus interiores, seus transeuntes - através de uma lente que transforma o visível em matéria onírica, a ser interpretada antes que se perca na consciência, no despertar.

(...) tenho dificuldades, como pela manhã, com um sonho desvanecido, à medida que os objetos readquirem seu tamanho em relação a mim, em rememorar o microscópio que ainda há pouco eu iluminava com meus espelhos, que eu fazia passar pelo pequeno diafragma da atenção. (ARAGON, 1996, p. 61) 
Louis Aragon "recoloca em seu pensamento" uma colagem de imagens: sua narrativa, marcada pela descrição exaustiva de prédios - casas de tolerância, meublés, casas de banho, lojas, etc. - e de personagens - prostitutas, barbeiros, engraxates, alfaiates, cabeleireiros, modistas, esposas em passeios furtivos -, é interrompida por breves diálogos entre alegorias, e pelas palavras da cidade: os dizeres das placas comerciais das lojas, trechos de jornais, carta de bebidas de café, informações de teatro, etc. A história presente nestes fragmentos é transformada na prosa poética em experiência estética.

A ênfase surrealista recai no sonho individual. Segundo Aragon, sua narrativa é uma maneira para se atingir o conhecimento de si mesmo, pois o que vê são seus limites interiores, "vistas ideais", completa o poeta, "que tenho de minhas leis, de minhas maneiras de pensar (...) método para me alforriar de certas coações, um meio de ter acesso, além de minhas forças, a um domínio ainda proibido" (ARAGON, 1996, p. 115). O mundo dos sonhos "é ao mesmo tempo familiar e desconhecido: familiar, em razão do estilo minuciosamente realista que permite ao espectador o reconhecimento dos objetos pintados; desconhecidos, por causa da estranheza dos contextos em que eles aparecem" (BRADLEY, 1999, p. 34).

Benjamin, por sua vez, ocupar-se-á dos sonhos coletivos e fa-lo-á através de "imagens ambíguas e enigmáticas" (TIEDEMANN apud BENJ AMIN, 2006, p. 18). Susan Buck-Morss assinala que este sonho coletivo era inconsciente em duplo sentido:

(...) de um lado pelo seu estado distraído de sonho, de outro porque era inconsciente de si mesmo, composto de indivíduos atomizados, consumidores que imaginavam o seu mundo de sonho mercadológico ser unicamente pessoal (a despeito de toda a evidência objetiva do contrário), e que experimentavam seu voto como membro na coletividade somente em um sentido alienante, como um componente anônimo da multidão (2002, p. 311).

Para compreender o fenômeno do sonho coletivo Benjamim recorrerá ao conceito de imagem dialética, que contraria todo o empenho da filosofia clássica em distinguir, em separar, sonho e razão, consciente e inconsciente, imaginação e realidade, vigília e sono.

A imagem dialética revela o saber do despertar. O limiar entre consciente e inconsciente, momento a ser apreendido em sua fugacidade. A imagem dialética traz resíduos da imagem onírica, mas não é uma abstração, ela está fundada em sujeitos históricos, ancorada na consciência de produtores de imagens como Aragon, que exploram o limiar entre sonho e despertar. As imagens dialéticas conduzem as imagens de sonho para o estado de vigília. Desta 
forma, o sonho, reconhecido como tal, é dissipado e o conhecimento histórico realizado.

E assim efetiva-se o despertar do sonho coletivo da fantasmagoria mercantil capitalista, experiência ligada a uma nova forma de escrever a história: "a arte de experienciar o presente como o mundo da vigília ao qual se refere o sonho que chamamos de o ocorrido. Elaborar o ocorrido na recordação do sonho" (BENJAMIN, 2006, p. $434,[K 1,3])$. É o momento do kairós, em que no despertar temos a rememoração do que realmente importa, antes que a avalanche de lembranças censure nossos sonhos coletivos.

A experiência surrealista da cidade traz um outro elemento importante que, no léxico benjaminiano, chamar-se-á iluminação profana, de inspiração materialista e antropológica, ou seja, expansão do espírito para além do êxtase religioso ou das impressões sob efeito de substâncias alucinógenas. Através da iluminação profana é possível perceber objetos corriqueiros, cotidianos - por exemplo, as passagens e os jardins, ruas e boulevares -, como extraordinários. De acordo com Benjamin, a habilidade de desorientar a percepção costumeira através da iluminação profana faz dessa prática um catalisador da revolução social. É, então, uma experiência revolucionária em que os surrealistas realizam um truque: trocam "o olhar histórico sobre o passado por um olhar político" (BENJAMIN, 1985, p. 26). Desta forma, mobilizam as energias da embriaguez para a revolução.

Benjamin se refere a $\mathrm{O}$ camponês de Paris e Nadja como obras que anunciam a iluminação profana, forma de "superação autêntica e criadora" sem necessariamente recorrer ao uso de qualquer espécie de narcótico (BENJ AMIN, 1985, p. 23).

Ler, pensar, esperar, se dedicar à flânerie são formas de iluminações profanas. Os surrealistas transformaram em experiência revolucionária o cenário desolado da metrópole moderna. Aragon e Breton "fazem explodir as poderosas forças 'atmosféricas' ocultas" nas coisas banais da vida cotidiana. "Imaginemos", propõe-nos o ensaísta, "como seria organizada uma vida que se deixasse determinar, num momento decisivo, pela última e mais popular das canções de rua" (BENJ AMIN,1985, p. 25).

A aposta no saber do despertar será um dos pontos de dissensão entre Benjamin e os princípios surrealistas. Para estes, realidade e sonho se embaraçam e o mito persiste sem ser reimpregnado pela razão.

Louis Aragon, em O camponês de Paris, indaga:

A cada dia modifica-se o sentimento moderno da existência. Uma mitologia se tece e se desenlaça. É uma ciência da vida que pertence unicamente àqueles que não têm experiência dela. Uma ciência viva que se engendra e se suicida. E 
quanto a mim (...) mereceria ainda participar desse milagre? Terei ainda por muito tempo o sentimento do maravilhoso cotidiano? (ARAGON, 1996, p. 42).

Não pôde me escapar por muito tempo que a propriedade de meu pensamento, a propriedade da evolução de meu pensamento em um mecanismo em todos os pontos análogo à gênese mítica e que, sem dúvida, eu não pensava nada que não determinasse imediatamente em meu espírito a formação de um deus, por mais efêmero, por menos consciente que ele fosse. Eu passeava portanto, com embriaguez, em meio a mil concreções divinas. Pus-me a conceber uma mitologia em marcha. Ela merecia propriamente o nome de mitologia moderna. (ARAGON, 1996, p. 142).

Mas a mitologia moderna, que aos olhos de Aragon é preciso decifrar como "sentimento do maravilhoso cotidiano", é dialeticamente pensada por Benjamin.

[...] enquanto Aragon persiste no domínio do sonho, deve ser encontrada aqui a constelação do despertar. Enquanto em Aragon permanece um elemento impressionista - a 'mitologia' - e a esse impressionismo se devem os muitos filosofemas vagos do livro [O camponês de Paris] - trata-se aqui da dissolução da 'mitologia' no espaço da história. Isso de fato só pode acontecer através do despertar de um saber ainda não consciente do ocorrido. (BENJ AMIN, 2006, p. 500, $[N, 1,9])$

Ainda que em Rua de mão única, a modernidade se apresente como uma utopia, nos textos posteriores, especialmente naqueles que estão na constelação de Passagens ${ }^{16}$, a fase perversa não pode ser obliterada. Benjamin desenvolve uma 'dialética do olhar' tendo como objeto de investigação os estilhaços da cultura de massa. Essa investigação propõe-se a subsumir a verdade filosófica sob estes escombros da história do homem na modernidade.

Também a definição de surrealismo, apresentada por Breton no Manifesto surrealista (1924), sinaliza para os limites da correspondência entre Benjamin e este movimento, pois se restringe a destacar os elementos formais do Surrealismo ainda que não tenham historicamente se subtraído da ebulição política de sua época ${ }^{17}$.

SURREALISMO. S.m. Automatismo psíquico puro, pelo qual se propõe a exprimir, seja verbalmente, seja por escrito, ou por qualquer outro meio, o funcionamento real do pensamento. Ditado do pensamento na ausência de todo e qualquer controle exercido pela razão, e fora de toda preocupação estética e moral. (BRETON, 1994, p. 11) 
O pressuposto do automatismo psíquico puro não está presente na escrita benjaminiana. No entanto, Benjamin exaltará o surrealismo afirmando ter sido este o primeiro movimento

(...) a ter pressentido as energias revolucionárias que
transparecem no "antiquado", nas primeiras construções de
ferro, nas primeiras fábricas, nas primeiras fotografias, nos
objetos que começam a extinguir-se, nos pianos de cauda,
nas roupas de mais de cinco anos, nos locais mundanos,
quando a moda começa a abandoná-los. (...) Antes desses
videntes e intérpretes de sinais, ninguém havia percebido de
que modo a miséria, não somente a social como a
arquitetônica, a miséria dos interiores, as coisas escravizadas
e escravizantes, transformavam-se em niilismo
revolucionário. (BENJAMIN, 1985, p. 25)

As reflexões benjaminianas são deliberadamente influenciadas pela teoria surrealista do sonho, em que o sonho se encontra enlaçado à ação. Tal teoria propõe o sonho acordado, a transferência da "ótica do sonho ao mundo da vigília". O poeta sonha acordado, seu corpo não se separa de sua mente e neste sonho ${ }^{18}$ pretende transformar a vida. A junção de sonho e ação será irresistivelmente atraente na posição política do Surrealismo.

Benjamin utiliza um jogo de palavras possível no idioma alemão para indicar a dimensão onírica do século XIX: é um espaço de tempo e um sonho de tempo" ${ }^{19}$, em que "a consciência coletiva mergulha em um sonho cada vez mais profundo" (BENJ AMIN, 2006, p. 434, [K, 4, 1]). E essa imersão será nas passagens. O filósofo faz um paralelo entre o sonho de um indivíduo que viaja pelo interior do próprio corpo e o sonho das multidões que perambulam pelas ruas. Diz Benjamin:

(...) assim como os ruídos e sensações de suas próprias entranhas, como a pressão arterial, os movimentos peristálticos, os batimentos cardíacos e as sensações musculares - que no homem sadio e desperto se confundem no murmúrio geral do corpo saudável - produzem, graças à inaudita acuidade de sua sensibilidade interna, imagens delirantes ou oníricas que traduzem e explicam tais sensações, assim também ocorre com o coletivo que sonha e que, nas passagens, mergulha em seu próprio interior. (BENJ AMI N, 2006, p. 432, [K, 1, 4])

Mas é preciso romper com esta homologia entre corpo humano e corpo coletivo para que se distingam os ritmos regulares do primeiro - e, portanto, sujeitos à eterna repetição - da arritmia característica dos processos que são históricos. Se o sujeito coletivo se sujeita às fantasmagorias da cidade ele repete, como se fossem processos orgânicos, o que de fato são processos históricos, passíveis, por conseguinte, de mudança. 
Aqui, novamente o olhar da criança retoma a cena (como o olhar do campesino) para realizar o que a percepção adulta não faz sem esforço: rememorar o novo. A criança vê outros significados para além daqueles convencionados pela cultura. Ela cria relações significativas insólitas. "A mesa sob a qual [a criança] se acocora é transformada no ídolo de madeira do templo (...). E atrás de uma porta, a criança é a própria porta." (BENJ AMIN, 1987b, p. 91). Desta forma, a infância "integra o novo mundo ao espaço simbólico." (BENJ AMIN, 2006, p. 435, [K, 1a, 3]).

II. A missão política do olhar seria interpretar as formas em que se manifestam os sonhos coletivos - as ruas, os monumentos, as construções, etc. É assim que deve ser, segundo Benjamin, a crítica ao século XIX.

Não a crítica ao seu mecanismo e maquinismo, e sim ao seu historicismo narcótico e à sua mania de se mascarar na qual não existe, contudo, um sinal de verdadeira existência histórica, que os surrealistas foram os primeiros a captar. (BENJ AMI N, 2006, p. 436, [K, 437])

Os surrealistas visavam ao conhecimento total do homem; Benjamin, ao conhecimento da história desse homem. E a metrópole moderna é o palco onde essa história é encenada.

Vimos, pois, que a relação indissolúvel estabelecida pelo surrealismo entre ação e sonho é preciosa para Benjamin, já que implica a constituição de um espaço político que não é mais medido pela contemplação. Os poetas surrealistas apresentaram a modernidade como um mundo de sonho e Benjamin afirmará que é preciso um despertar coletivo. Constrói uma crítica demolidora e denuncia que as mudanças espaciais não são meros ajustes urbanísticos, decorrentes de escolhas formais, mas materialização de práticas políticas que, por vezes, estão a serviço de projetos totalitários, contrários à necessária emancipação humana.

Benjamin coloca-se como detetive do inconsciente coletivo que lê os símbolos da cidade como símbolos mnemônicos, "mas também símbolos 'histéricos': a cidade como sobreposição de diversas épocas mantém o passado materializado na pedra que faz surgir seu passado em presentes novos. Sendo assim, a cidade emerge do esquecimento na consciência do presente." (MATOS, 2005, p. 175) e torna-se tarefa filosófica promover o rompimento "com o conformismo das visões transmitidas e com a falsa continuidade das tradições" (ROCHLITZ, 2003, p. 274).

Benjamin torna visíveis as linhas da temporalidade histórica do mundo moderno: o tempo do inferno. O tempo infernal faz um pas de deux com a Idade do Ouro. Neste bailado dialético, sob o compasso da moda que sempre faz voltar o velho disfarçado em novidade, 0 
sentimento é o do tédio, a prática privilegiada é a da jogatina, e as condições materiais são as do pauperismo.

\section{Referências Bibliográficas}

ARAGON, L. O camponês de Paris. Apresentação, tradução e notas de Flávia Nascimento. Rio de Janeiro: I mago, 1996.

BRETON, A. Nadja. Trad. Ernesto Sampaio. 2ª ed. Lisboa: Estampa, 1972.

Manifestes du surréalisme. Paris: Gallimard, 1994.

BENJAMIN, W. Correspondance 1910-1928. Trad. Guy Petitdemange. Paris: Aubier-Montaigne, 1979.

O Surrealismo. O último instantâneo da inteligência europeia. In: Magia e técnica, arte e política: ensaio sobre literatura e história da cultura. Obras escolhidas. v. 1. Trad. Sérgio Paulo Rouanet. São Paulo: Brasiliense, 1985.

Origem do drama barroco alemão. Trad. Sérgio Paulo Rouanet. São Paulo: Brasiliense, 1986.

Documentos de cultura, documentos de barbárie: escritos escolhidos / Seleção e apresentação Willi Bolle. Trad. Celeste H. M. Ribeiro de Sousa, et al. São Paulo: Cultrix, Editora da Universidade de São Paulo, 1986b.

. Rua de mão única. Obras escolhidas. v. 2. Trad. Rubens Rodrigues Torres Filho. São Paulo: Brasiliense, 1987a.

. Infância em Berlim por volta de 1900. In: Rua de mão única. Obras escolhidas. v. 2. Trad. José Carlos Martins Barbosa. São Paulo: Brasiliense, 1987b, p. 71-142.

O conceito de Crítica de Arte no Romantismo alemão. Tradução, prefácio e notas de Márcio Seligmann-Silva. São Paulo: EDUSP: Iluminuras, 1993.

Walter Benjamin. Obras escolhidas, v. 3. Charles Baudelaire um lírico no auge do capitalismo. Trad. J osé Carlos Martins Barbosa e Hemerson Alves Baptista. São Paulo: Brasiliense, 1989.

Passagens. Belo Horizonte: Editora UFMG; São Paulo: Imprensa Oficial do Estado de São Paulo, 2006.

BOLLE, W. A metrópole como medium-de-reflexão. In: SELIGMANNSILVA, M. (Org.). Leituras de Walter Benjamin. São Paulo: FAPESP, Annablume, 1999, p. 89-109.

BRADLEY, F. Surrealismo. Trad. Sérgio Alcides. São Paulo: Cosac \& Naify, 1999.

BUCK-MORSS, S. Dialética do olhar: Walter Benjamin e o projeto das Passagens. Trad. Ana Luiza de Andrade. Revisão técnica de David Lopes da Silva. Belo Horizonte: Editora UFMG; Chapecó/SC: Editora Universitária Argos, 2002.

CASSOU, J. Panorama das artes plásticas contemporâneas. Trad. José Saramago. Lisboa: Editorial Estúdios Cor, 1962. 
COELHO NETO, J. T. Moderno Pós-Moderno. Porto Alegre: L\&PM, 1986.

JENNINGS, M. Walter Benjamin and the European avant-garde. In: FERRIS, D. S. (Ed.). The Cambridge Companion to Walter Benjamin. Cambridge: Cambridge University Press, 2004, p. 18-34. GOMBRICH, Ernst H. Arte e ilusão: um estudo da psicologia da representação pictórica. 4ạed. Trad. Raul de Sá Barbosa. Revisão da tradução de Mônica Stahel. São Paulo: Martins Fontes, 2007.

MATOS, O. C. F. O sex appel da imagem e a insurreição do desejo. In: NOVAES, A. (Org.). Muito além do espetáculo. São Paulo: Editora Senac São Paulo, 2005, p. 168-180.

ROCHLITZ, R. O desencantamento da arte: a filosofia de Walter Benjamin. Trad. Maria Elena Ortiz Assumpção. Bauru: EDUSC, 2003.

\author{
Endereço para correspondência \\ Vanessa Madrona Moreira Salles \\ Rua Vereador Teixeira de Azevedo, 140/201, CEP 31170-140, Belo Horizonte, MG, \\ Brasil
}

Endereço eletrônico: vanessasalles@uol.com.br

Recebido em: 13/03/2010

Aceito para publicação em: 15/04/2010

Acompanhamento do processo editorial: Ariane P. Ewald e Jorge Coelho Soares

\begin{abstract}
Notas
* Doutora em Filosofia pela Universidade de São Paulo; professora da Fundação Mineira de Educação e Cultura - FUMEC, Belo Horizonte - MG, Brasil.

${ }^{1}$ Durante o Segundo Império (1853-1870), Paris passará por grandes transformações urbanísticas realizadas pelo chefe administrativo da cidade, Barão Georges Eugène Haussmann: melhoria das condições sanitárias, modernização das instalações públicas e dos transportes, construção da ópera de Paris e do mercado central Les Halles, criação de parques e dos grandes bulevares, "o que implicou na demolição de vários bairros antigos de Paris e de numerosas passagens construídas durante a primeira metade do século XIX" (Léxico de nome, conceitos, instituições. In: BENJAMIN, 2006, p. 1080). "A verdadeira finalidade dos trabalhos de Haussmann era proteger a cidade contra a guerra civil. Queria tornar impossível para sempre a construção de barricadas em Paris. (...) A largura das ruas deve impossibilitar que sejam erguidas barricadas, e novas ruas devem estabelecer 0 caminho mais curto entre os quartéis e os bairros operários. Os contemporâneos batizam o empreendimento de 'embelezamento estratégico'." (BENJ AMIN, 2006, p. 50)

${ }^{2}$ J. J. Honegger, Grundsteine einer allgemeinen Kulturgeschichte der neusten Zeit, V, Leipzig, 1874, p. 326. In: BENJ AMIN, 2006, p. 163, [E, 1a, 1].

${ }^{3} A$ definição do termo moderno é problemática por ser uma complexa noção estética, filosófica, sociológica e histórica. É simultaneamente uma categoria histórica e uma categoria tipológica. É categoria histórica no sentido em que se refere a um determinado momento ou manifestação histórica, portanto, indica um período da história da filosofia que parte do Iluminismo, no século XVIII, ou o período da história da arte e da literatura do século XX. É uma categoria tipológica quando utilizada com pretensões universalizantes para designar o novo, ou o atual. Este sentido tipológico está na origem etimológica da palavra moderno, derivada do
\end{abstract}


latim modo que se refere àquilo que é de agora, do instante, recente ou circunstancial. O termo modernus surge na Alta Idade Média com o sentido de "atual" e de "novo". Cf. Coelho Neto, 1986.

${ }^{4}$ Susan Buck-Morss (2002), em Dialética do olhar, discorre sobre as quatro cidades importantes na vida de Walter Benjamin: Nápoles, Moscou, Paris e Berlim. A autora mostra que o Benjamin "lia" os edifícios, os comportamentos, os arranjos espaciais, as imagens como expressões objetivas de um mundo que atravessava profundas mutações sociais. Cf. p. 50-64.

${ }^{5}$ Benjamin viaja a Moscou em dezembro de 1926 e fica nessa cidade até $1^{\circ}$ de fevereiro do ano seguinte. Resultam desta experiência o livro Diário de Moscou e o ensaio "Moscou".

${ }^{6} \mathrm{Em} 1926$ foi publicado o ensaio "Nápoles".

${ }^{7}$ Aléxis Martin. Physiologie de l'asphalte. Le Bohème, I, n. 3, 15 abr. 1855, apud BENJ AMI N, 2006, p. 466, [M, 2a, 3].

${ }^{8}$ Destacamos O conceito de Crítica de Arte no Romantismo alemão (1919), o ensaio sobre as Afinidades eletivas (1924), e Origem do drama barroco alemão (1925).

"Segundo Michael Jennings, o ambiente que proporcionou a "descoberta" benjaminiana de temas como arte industrial, cultura de massa, fotografia, etc, foi a convivência com o G-Grupo, coletivo do início dos anos 20 que contava com a participação de artistas, arquitetos, intelectuais de vanguarda. Participavam: Laslo Moholy-Nagy, artista húngaro, o arquiteto Mies van der Rohe, Lissitsky, construtivista russo, dentre outros. Este grupo notabilizou-se por reunir o construtivismo, o dadaísmo, e o despertar do surrealismo. (JENNINGS, 2004, p. 2123).

${ }^{10}$ Por exemplo, durante a produção de Rua de mão única, Benjamin recorre a características formais vanguardistas - como o uso de aforismos e a descrição material do mundo - que mostram uma coerência interna, apesar de o estilo antinarrativo tornar "claro que as estratégias vanguardistas são ditadas não pela estética, mas por preocupações políticas" (JENNINGS, 2004, p. 25). Neste livro Benjamin utiliza técnicas e temas surrealistas. A cidade é vista com olhos imaginativos, erotizantes, que se atêm a objetos, sonhos, lugares, pessoas, aparentemente insignificantes, e transmuta-os em fonte de iluminação crítica. É a modernidade compreendida como um mundo de sonhos. Um mundo de sonhos fragmentados, por vezes, arruinado.

11“Minhas pesquisas e meus interesses me dão o sentimento de estar isolado na Alemanha entre os homens de minha geração. Acontecem na França fenômenos particulares, sobretudo entre os escritores - Giraudoux, Aragon -, o movimento surrealista, onde eu vejo ser discutido o que me preocupa também." (BENJAMIN, 1979, p. 406)

${ }^{12}$ Em 1933, Benjamin deixa Berlim e se fixa em Paris. Vivenciará, então, a cidade na condição de imigrante, que frequenta suas ruas, visita seus monumentos, convive com sua multidão. Como a lontra no zoológico, ficará nas profundezas da Bibliothèque Nationale.

${ }^{13}$ No final de seu romance, Breton refere-nos sua tentativa de fotografar lugares que ele havia cotejado em sua narrativa, a qual, no entanto, não fora plenamente efetivada porque muitos deles já haviam sido destruídos.

${ }^{14}$ Talvez tenha contribuído para esta transformação perceptiva a experiência do poeta nos campos de batalha da Primeira Guerra Mundial. Aragon fora convocado, em 1917, para atuar como médico-auxiliar. Foi neste período que conheceu André Breton, mobilizado para o mesmo hospital como estudante-médico-auxiliar. (NASCIMENTO, Flávia. Apresentação. In: ARAGON, 1996, p. 12) Benjamin, em "Experiência e pobreza" (BENJAMIN, 1986b), trata das alterações perceptivas decorrentes da experiência da guerra e lança um olhar de desengano sobre a mentira da civilização, a saturação dos privilegiados, a liquidação do patrimônio cultural, procedimento afim ao dos poetas surrealistas. 
${ }^{15}$ É exemplar o quadro de René Magritte intitulado Ceci n'est pas une pipe, em que o artista leva-nos a duvidar de nossa percepção das coisas, confundindo o limiar entre o real e o imaginário.

${ }^{16}$ Susan Buck-Morss constrói um diagrama em que apresenta a relação cronológica entre o material desenvolvido por Benjamin nas Passagens e os ensaios redigidos. Segundo a autora, "(ideias para inúmeras peças menores - resenhas de literatura contemporânea, filme, fotografia - foram emprestadas, às vezes inteiramente, do Passagen-Werk) mas representam os artigos mais importantes de Benjamin durante o fim das décadas dos anos vinte e dos trinta, e estão relacionados ao complexo Passagen como indicadores visíveis do iceberg de sua atividade intelectual." Cf. BUCK-MORSS, 2002, p. 76-77.

${ }^{17}$ Sobre o posicionamento político dos participantes do movimento surrealista, Flávia Nascimento apresenta o seguinte esclarecimento: “( (..) no segundo manifesto Surrealista, publicado por Breton em 1929, o grupo tomou posição favorável à revolução proletária, acrescentando à necessidade de mudar a vida (...) a urgência de 'transformar o mundo' (segundo a divisa de Marx). A opção pelo materialismo dialético tornava-se desta forma clara, impondo a questão seguinte: os surrealistas deveriam ou não aderir ao Partido Comunista? Tal questão provocou mais um cisma no grupo surrealista. André Breton e Paul Éluard aderiram ao PCF em 1927, mas sua permanência nele não durou mais do que algumas semanas. Aragon aderiu na mesma época, mas, ao contrário dos dois amigos, morreria comunista. Sua adesão desencadearia a ruptura com o grupo." (Flávia Nascimento, Apresentação. In: ARAGON, 1996, p. 15).

18“'Freud tinha escrito que 'as idéias no sonho [... são] realizações de desejos' [Interpretação dos sonhos], que, devido a sentimentos ambivalentes, aparecem de forma censurada, e daí, distorcida. O desejo verdadeiro (latente) pode ser quase invisível, em um nível manifesto, e só se pode ter acesso a ele através da interpretação do sonho. Assim: 'Um sonho é a realização (disfarçada) de um desejo (suprimido, reprimido).' Se considerada a classe burguesa como geradora do sono coletivo, então as tendências socialistas daquele industrialismo que ela própria criou, pareceriam capturá-la, inevitavelmente, em uma situação de desejo ambivalente. A burguesia deseja afirmar a produção industrial da qual obtém lucros; ao mesmo tempo deseja negar o fato que o industrialismo cria as condições que ameaçam a continuação do domínio de sua própria classe." (BUCK-MORSS, 2002, p.337).

${ }^{19}$ Zeitraum (espaço de tempo), Zeit-traum (sonho de tempo). 